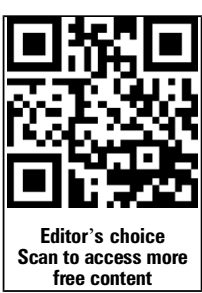

'Department of Medicine, University of California San Francisco, California, USA ${ }^{2}$ Department of Environmental Health Sciences, School of Public Health, University of California, Berkeley, California, USA

${ }^{3}$ School of Nursing, University of California, San Francisco,

California, USA

${ }^{4}$ Center for Health Studies, Universidad del Valle de Guatemala, Guatemala ${ }^{5}$ Department of Public Health and Policy, University of Liverpool, Liverpool, UK

Correspondence to Dr John R Balmes, University of California San Francisco, Box 0843, San Francisco CA 94143-0843, USA:

John.Balmes@ucsf.edu

Received 7 September 2015 Revised 5 December 2015 Accepted 15 December 2015 Published Online First 10 March 2016

\section{Linked}

- http://dx.doi.org/10.1136/ thoraxinl-2015-208241

- http://dx.doi.org/10.1136/ thoraxinl-2016-208318

\section{CrossMark}

$$
\begin{aligned}
& \text { To cite: Heinzerling AP, } \\
& \text { Guarnieri MJ, Mann JK, } \\
& \text { et al. Thorax 2016;71: } \\
& \text { 421-428. }
\end{aligned}
$$

\title{
Lung function in woodsmoke-exposed Guatemalan children following a chimney stove intervention
}

\author{
Amy P Heinzerling, ${ }^{1}$ Michael J Guarnieri, ${ }^{1}$ Jennifer K Mann, ${ }^{2}$ Janet V Diaz, ${ }^{1}$ \\ Lisa M Thompson, ${ }^{3}$ Anaite Diaz, ${ }^{4}$ Nigel G Bruce, ${ }^{5}$ Kirk R Smith, ${ }^{2}$ John R Balmes ${ }^{1,2}$
}

\begin{abstract}
Rationale Household air pollution (HAP) from solid fuel combustion is a major contributor to the global burden of disease, with considerable impact from respiratory infections in children. The impact of HAP on lung function is unknown.

Objectives The Childhood Exposure to Respirable Particulate Matter (CRECER) prospective cohort study followed Guatemalan children who participated in the Randomised Exposure Study of Pollution Indoors and Respiratory Effects (RESPIRE) trial of a chimney stove intervention to determine the effect of early childhood HAP exposure on growth of lung function.

Methods RESPIRE households with pregnant women or infant children were randomised to receive a chimney stove at the beginning or at the end of the 18-month trial. During CRECER, a subset of these children, as well as children from households with newly installed stoves, were followed with spirometry beginning at age 5. Biomass smoke exposure was measured using personal carbon monoxide tubes. Two-stage regression models were employed to analyse associations with lung function growth.

Measurements and main results Longitudinal peak

\section{Key messages}

What is the key question?

- Previous studies have shown decreased lung function growth associated with outdoor air pollution, but no longitudinal studies to date have examined the association between household air pollution (HAP) from biomass smoke and childhood lung function.

\section{What is the bottom line?}

- Using follow-up data after a randomised stove intervention trial, longer use of an open fire was associated with a significant decrease in peak expiratory flow rates and a large non-significant decrease in $\mathrm{FEV}_{1}$.

\section{Why read on?}

- Because HAP from solid fuel combustion is the third greatest contributor to the global burden of disease, it is important to understand the relationship between early-life exposure to HAP and growth of lung function.
\end{abstract} expiratory flow (PEF) and FEV ${ }_{1}$ data were available for 443 and 437 children, respectively, aged 5-8 (mean follow-up 1.3 years). Decreases in PEF growth of $173 \mathrm{~mL} / \mathrm{min} /$ year $(95 \% \mathrm{Cl}-341$ to -7$)$ and $\mathrm{FEV}_{1}$ of $44 \mathrm{~mL} /$ year ( $95 \% \mathrm{Cl}-91$ to 4) were observed with stove installation at 18 months compared with stove installation at birth in analyses adjusted for multiple covariates. No statistically significant associations were observed between personal HAP exposure and lung function.

Conclusions A significant decrease in PEF growth and a large non-significant decrease in $\mathrm{FEV}_{1}$ growth were observed with later stove installation. Additional studies including longer follow-up and cleaner stoves or fuels are needed.

\section{INTRODUCTION}

Over 2.4 billion people worldwide, most in lowincome and middle-income countries, use biomass fuels such as wood, dung and crop residues for cooking. These fuels are typically burned in open fires in poorly ventilated homes, releasing significant quantities of pollutants including particulate matter (PM), carbon monoxide (CO), nitrogen oxides and polycyclic aromatic hydrocarbons. ${ }^{1-3}$ In homes with open fires, indoor concentrations of PM have been found to be 10 or even 100 times higher than maximum levels recommended by WHO guidelines. ${ }^{4}$ Household air pollution (HAP) from solid fuels is estimated to be responsible for 3.5 million premature deaths and $4.3 \%$ of disability-adjusted life years lost annually, making it the third greatest contributor to the global burden of disease following high blood pressure and tobacco smoke. ${ }^{5}$

Women who traditionally undertake the majority of household tasks and the young children who accompany them tend to have the highest biomass smoke exposure. ${ }^{6}{ }^{7}$ Young children are exposed during a critical period of lung development; new alveoli develop and continue to grow in size through adolescence. ${ }^{8}$ Numerous studies have shown increased risks of acute lower respiratory infections associated with biomass smoke exposure. $^{7-11}$ Early childhood respiratory infections, along with inflammation and oxidative stress from air pollutant exposure, may affect lung development and predispose children to chronic illnesses such as asthma and COPD later in life.

Outdoor air pollution studies have found increased concentrations of pollutants, including $\mathrm{PM}$, to be associated with decreased lung function growth in children. ${ }^{12-16}$ However, studies of HAP 
and lung function in children have been more limited. Several cross-sectional studies have found associations between biomass use and reduced lung function in children, ${ }^{17-22}$ but they have been limited by their cross-sectional designs and lack of direct exposure assessment, and most could not address important confounders. One longitudinal study in China found a decrease in lung function growth in children living in coal-burning homes compared with those in homes using gas; among coal-using homes, lung function growth was higher in homes with improved ventilation. ${ }^{23}$ However, the emissions from coal stoves are somewhat different from those in which biomass is burned. No longitudinal studies have examined the effect of HAP from biomass fuels on lung function in children.

Using longitudinal spirometry data from a cohort of children who participated in the first randomised controlled clinical trial of a chimney stove intervention designed to reduce HAP, this study sought to investigate whether early childhood exposure to biomass smoke was associated with lower lung function growth later in childhood.

\section{METHODS}

\section{Study design and participants}

In the Randomised Exposure Study of Pollution Indoors and Respiratory Effects (RESPIRE), which took place from 2002 to 2004, 534 households in rural Guatemala that cooked exclusively over open fires and included a pregnant woman or young infant were randomised to receive a stove with a chimney to vent emissions to the outdoors (plancha) or no intervention. This stove is locally available and was found in pilot studies to be acceptable to the local population and efficacious in reducing indoor pollution levels. ${ }^{24}$ At the end of the 18-month intervention period, all households in the control group received the chimney stove. The design of the RESPIRE study has been published in detail elsewhere. ${ }^{9} 25$

The Chronic Respiratory Effects of Early Childhood Exposure to Respirable PM (CRECER) cohort study took place from 2006 to 2009 and included a subset of RESPIRE households, as well as a group of new households. Eligible new households were located in the same region as RESPIRE households, cooked exclusively over open fires, and included one child in the same age range as the RESPIRE children (3-4 years old at the time of enrolment in CRECER), as well as one infant $<6$ months of age. All new CRECER households received the chimney stove midway through the CRECER study, allowing for a 12-18 month period of observation prior to stove installation. This resulted in three distinct groups with different durations of stove use (table 1): those in the RESPIRE intervention group receiving a stove within 6 months of birth (hereafter Group 1), those in the RESPIRE control group receiving a stove around 18 months of age (Group 2) and those in the new CRECER

\begin{tabular}{lll} 
Table 1 & Study groups & \\
\hline & Group description & Timing of stove installation \\
\hline Group 1 & $\begin{array}{l}\text { RESPIRE intervention } \\
\text { households }\end{array}$ & Within 6 months of birth \\
Group 2 & $\begin{array}{l}\text { RESPIRE control } \\
\text { households }\end{array}$ & $\begin{array}{l}\sim 18 \text { months, following the conclusion of } \\
\text { the RESPIRE trial }\end{array}$ \\
Group 3 & New CRECER households & $\sim 57$ months, during the CRECER study \\
\hline $\begin{array}{l}\text { CRECER, Childhood Exposure to Respirable Particulate Matter; RESPIRE, Randomised } \\
\text { Exposure Study of Pollution Indoors and Respiratory Effects. }\end{array}$
\end{tabular}

group receiving a stove during CRECER, when the study child was around age 5 and their infant sibling was around 1824 months of age (Group 3).

\section{Biomass smoke exposure}

Small passive-diffusion colorimetric tubes were worn by the children for a period of 48 -h every 3 months during RESPIRE and every 6 months during CRECER to measure exposure to $\mathrm{CO}$, as described elsewhere. ${ }^{24}$ As $\mathrm{CO}$ measurements from the first 18 months of life were unavailable for new CRECER participants (Group 3) who were enrolled at age 3-4, personal CO measurements from their infant siblings taken prior to stove installation were used as a proxy for these participants' exposure during the first 18 months of life in the exposure-response analyses.

Personal CO exposure correlates well with exposure to fine PM $\left(\mathrm{PM}_{2.5}\right)$ in this population of wood-fuel users ${ }^{26}$ and was therefore used as a proxy for $\mathrm{PM}_{2.5}$ exposure.

\section{Spirometry}

Spirometry was performed beginning at 5 years of age and repeated every 6 months during CRECER follow-up. Using an EasyOne spirometer (ndd Medical Technologies, Inc, Andover, Massachusetts, USA), children performed spirometry guided by a trained physician and following American Thoracic Society performance criteria. Individual curves were graded manually by one of two experienced reviewers blinded to intervention group; only lung function measurements from curves meeting acceptability criteria were included in this analysis. As the children were quite young, reproducible $\mathrm{FEV}_{1}$ and peak expiratory flow (PEF) measurements from good efforts were retained for analysis even when FVC measurements were not of adequate quality. Per cent predicted lung function was calculated using Global Lung Function Initiative (GLFI) equations. ${ }^{27}$

\section{Statistical analysis}

Linear regression methods were used to analyse whether there were differences in lung function growth based on study group or HAP exposure using a two-stage model. The first stage was a linear regression of lung function variables on age, by subject, generating a separate lung function growth slope for each subject for each spirometric variable. Only children with acceptable spirometry from two or more sessions were included. In the second stage, a regression of the subject-specific growth slopes was conducted on study group, to estimate average lung function growth by study group. Secondary exposure-response analyses using log-transformed mean personal CO measurements from the first 18 months of life were also conducted, to estimate change in lung function growth associated with changes in HAP exposure. All 95\% CIs were obtained using a robust estimator.

Sex, height at first spirometry, annual change in height and secondhand smoke exposure were included as a priori confounders in all second-stage models. Other covariates including maternal education, paternal education, asset index and temazcal (wood-fuelled sauna bath) use were assessed for inclusion by backwards elimination. Variables were retained in the final model if either their $p$ value was $<0.1$ or if eliminating them from the model resulted in a change in the $\beta$ coefficient for the main predictor of $>10 \%$. The asset index, used as a marker of socioeconomic status, is a number from 0 to 7 calculated based on possession of any of the following items in a household (each adding 1 point): television, radio, refrigerator, bicycle, motorcycle, automobile or cell phone. Paternal and maternal education 
levels were categorised as no formal education, elementary school or greater than elementary school. The temazcal is used for bathing and cleaning and has been found to lead to intermittent, high exposures to biomass smoke. ${ }^{28} 29$ Temazcal use was categorised based on whether participants accompanied their parents into the temazcal always, sometimes or never. Secondhand smoke exposure was present if any individual in the participant's household was a current smoker. All demographic variables were assessed by questionnaire administered at the beginning of the CRECER study.

Univariate analyses comparing stove groups used $\chi^{2}$ tests for categorical variables, and analysis of variance for normally distributed continuous variables or their logarithmic transformations, using the Scheffé procedure to assess pairwise differences between groups. Statistical analysis was performed using Stata V.11.2.

\section{Ethical considerations}

Both RESPIRE and CRECER protocols were approved by the research ethics committees of the University of California, Berkeley, and the Universidad del Valle in Guatemala prior to study initiation. CRECER was also approved by the research ethics committee at the University of California, San Francisco. Participants were enrolled via oral informed consent, which was conducted by trained local field workers fluent in participants' primary language (Mam). Primary caregivers (typically mothers) provided consent for their participating children.

\section{RESULTS}

Five hundred and fifty-seven children were initially enrolled in CRECER, including 194 from each arm of the RESPIRE trial and 169 from new households. Graded spirometry results were available for a total of 506 children, including 175 from Group 1, 180 from Group 2 and 151 from Group 3 (figure 1).

Child and household demographic variables were similar across stove groups (table 2). Average age of first spirometry across all groups was 5.4 years, and ages ranged from 5 to 8 years during the study period.

The mean number of spirometry sessions per child was 3.6, and 495 children $(98 \%)$ had two or more spirometry sessions. Average length of follow-up was 1.3 years, and there were 1809 total spirometry sessions among all children. One thousand three hundred and ninety-eight sessions (77\%) had at least one acceptable $\mathrm{FEV}_{1}$ measurement by manual grading criteria; 1306 (72\%) had at least one acceptable FVC and $\mathrm{FEF}_{25-75}$ measurement, and 1425 (79\%) had at least one acceptable PEF measurement.

Average personal $\mathrm{CO}$ exposure concentrations during the first 18 months of life varied across stove groups (table 3). Participants in Group 1 had a mean CO of 1.18 ppm (SD 0.5) following stove installation, which was significantly lower than average $\mathrm{CO}$ in Group $2(1.96 \mathrm{ppm}, \mathrm{SD} 0.8)$ and Group 3 (1.67 ppm, SD 0.8) whose measurements were taken prior to stove installation $(\mathrm{p}<0.001$ for both pairwise comparisons). A significant difference was also observed between average exposures in Groups 2 and $3(\mathrm{p}=0.001)$. For the participants in Group 1, mean baseline CO level prior to stove installation was $2.19 \mathrm{ppm}$, representing a decrease of $46 \%(\mathrm{p}<0.001)$ after stove installation. The distributions for personal CO exposure concentrations were positively skewed; their natural log transformations were more normally distributed and were used in all statistical analyses.

Mean $\mathrm{FEV}_{1}$ at first spirometry was $0.92 \mathrm{~L}$ in Group $1,0.91 \mathrm{~L}$ in Group 2 and $0.82 \mathrm{~L}$ in Group $3(\mathrm{p}=0.19)$. Average per cent predicted $\mathrm{FEV}_{1}$ at first spirometry was 110\%, 108\% and 104\% in Groups 1, 2 and 3, respectively. Baseline measurements and per cent predicted values of FVC, $\mathrm{FEF}_{25-75}$ and PEF were also lower in Group 3 compared with Groups 1 and 2, though none of these differences was statistically significant (table 4).

Average $\mathrm{FEV}_{1}$ growth was $144 \mathrm{~mL} /$ year in Group 1, 100 in Group 2 and 109 in Group $3(\mathrm{p}=0.14)$, and average FVC growth was $172 \mathrm{~mL} /$ year in Group 1, 137 in Group 2 and 146 in Group $3(p=0.43)$. Out of 1324 spirometry sessions with

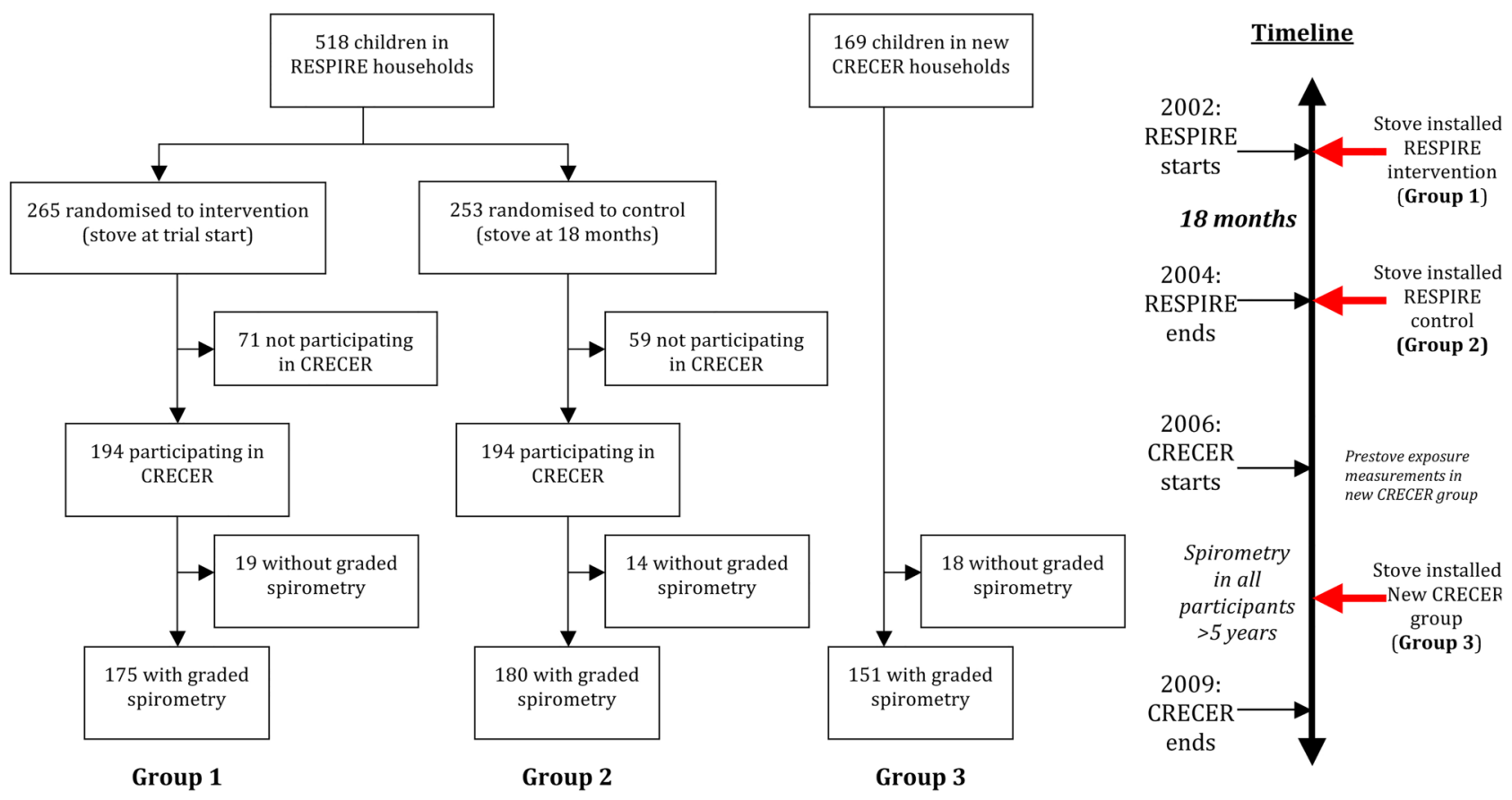

Figure 1 Study diagram and timeline. CRECER, Childhood Exposure to Respirable Particulate Matter; RESPIRE, Randomised Exposure Study of Pollution Indoors and Respiratory Effects. 
Table 2 Demographic characteristics by study group

\begin{tabular}{|c|c|c|c|c|}
\hline & $\begin{array}{l}\text { Group } 1 \\
\mathrm{~N}=175, \\
\text { mean (SD) } \\
\text { or } \mathrm{n}(\%)\end{array}$ & $\begin{array}{l}\text { Group } 2 \\
n=180 \text {, } \\
\text { mean }(S D) \\
\text { or } n(\%)\end{array}$ & $\begin{array}{l}\text { Group } 3 \\
n=151 \text {, } \\
\text { mean (SD) } \\
\text { or } n(\%)\end{array}$ & p Value* \\
\hline Age at first spirometry & $5.3(0.2)$ & $5.3(0.2)$ & $5.4(0.3)$ & $<0.0001$ \\
\hline Baseline height $(\mathrm{cm})$ & $97(4.1)$ & $97(4.2)$ & $98(4.4)$ & 0.70 \\
\hline $\begin{array}{l}\text { Number of spirometry } \\
\text { sessions per child }\end{array}$ & $3.8(1.1)$ & $3.7(1.1)$ & $3.2(1.3)$ & $<0.0001$ \\
\hline \multicolumn{5}{|l|}{ Gender } \\
\hline Male & $85(49)$ & $88(49)$ & $72(48)$ & 0.98 \\
\hline Female & $90(51)$ & $92(51)$ & $79(52)$ & \\
\hline \multicolumn{5}{|l|}{ Maternal education } \\
\hline None & $61(35)$ & 69 (38) & $43(28)$ & 0.28 \\
\hline Elementary school & $107(61)$ & $108(60)$ & $106(70)$ & \\
\hline Middle school & $4(2)$ & $1(1)$ & $1(1)$ & \\
\hline High school & $3(2)$ & $2(1)$ & $1(1)$ & \\
\hline \multicolumn{5}{|l|}{ Paternal education } \\
\hline None & $18(11)$ & $24(14)$ & $18(12)$ & 0.73 \\
\hline Elementary school & $126(76)$ & $123(71)$ & $107(71)$ & \\
\hline Middle school & $8(5)$ & $6(3)$ & 7 (5) & \\
\hline High school & $14(8)$ & $20(12)$ & 149 (13) & \\
\hline Unknown & $9(5)$ & $7(4)$ & $0(0)$ & \\
\hline Asset index (0-7) & $1.67(1.0)$ & $1.72(1.1)$ & $1.55(1.0)$ & 0.36 \\
\hline Smoker present in home & $13(7)$ & $22(12)$ & $14(9)$ & 0.31 \\
\hline \multicolumn{5}{|l|}{ Child use of temazcal } \\
\hline Always & $142(81)$ & $135(75)$ & $114(76)$ & 0.38 \\
\hline Sometimes & $123(13)$ & $31(17)$ & $230(20)$ & \\
\hline Never & $10(6)$ & $14(8)$ & $7(6)$ & \\
\hline
\end{tabular}

both acceptable $\mathrm{FEV}_{1}$ and FVC measurements, only 19 sessions, distributed among 17 children (3.4\% of study participants), had $\mathrm{FEV}_{1} / \mathrm{FVC}$ ratios $<0.7$ (table 4 ).

In the two-stage regression, lower $\mathrm{FEV}_{1}, \mathrm{FVC}, \mathrm{FEV}_{1} / \mathrm{FVC}$ ratio, $\mathrm{FEF}_{25-75}$ and $\mathrm{PEF}$ growth rates were observed in Groups 2 and 3 compared with Group 1 (table 5). A statistically significant decrease of $173 \mathrm{~mL} / \mathrm{min} /$ year in PEF growth rate was seen in Group 2 compared with Group 1 (95\% CI -341 to -7 ; $\mathrm{p}=0.048)$. A borderline statistically significant decrease of
Table 3 Average carbon monoxide (CO) exposures during Randomised Exposure Study of Pollution Indoors and Respiratory Effects (RESPIRE) and Childhood Exposure to Respirable Particulate Matter (CRECER) by study group*

\begin{tabular}{|c|c|c|c|c|}
\hline & $\begin{array}{l}\text { Group 1, } \\
\text { mean } \\
\text { (SD) }\end{array}$ & $\begin{array}{l}\text { Group 2, } \\
\text { mean } \\
(\mathrm{SD})\end{array}$ & $\begin{array}{l}\text { Group 3, } \\
\text { mean } \\
\text { (SD) }\end{array}$ & p Value \\
\hline $\begin{array}{l}\text { Average RESPIRE CO† } \\
\text { (ppm) }\end{array}$ & $1.18(0.5)$ & $1.97(0.8)$ & $1.66(0.8)$ & $<0.0001$ \\
\hline Average CRECER CO (ppm) & $0.88(0.7)$ & $0.88(0.5)$ & $1.28(0.6)$ & $<0.0001$ \\
\hline
\end{tabular}

$44 \mathrm{~mL} /$ year in $\mathrm{FEV}_{1}$ growth rate was also seen in Group 2 compared with Group 1 (95\% CI -91 to $4 ; \mathrm{p}=0.07)$.

In the secondary exposure-response analysis, there were no statistically significant associations between personal CO exposure during the first 18 months of life and any lung function variable (table 6). A sensitivity analysis was also conducted adjusting for exposures later in life (during the CRECER study period). There were no significant differences in results compared with the analysis of early life exposures alone.

An additional sensitivity analysis was conducted, restricted to only participants from the two original RESPIRE groups (Groups 1 and 2), excluding participants from the new CRECER group (Group 3). In this analysis with reduced statistical power, although the magnitude of effects was similar to those observed in the full analysis, there were no significant associations between either study group or personal CO exposure and lung function growth.

The final second-stage model used for all adjusted analyses included the following covariates: gender, height at first spirometry, annual change in height, maternal education and secondhand smoke exposure. Paternal education, asset index and temazcal use were assessed but excluded from the final model.

\section{DISCUSSION}

This study presents longitudinal follow-up data from a cohort of children enrolled in the first randomised controlled clinical trial
Figure 2 An open fire (A) and a study-provided chimney stove (B) in study participants' homes (photo credits: Lisa M Thompson).
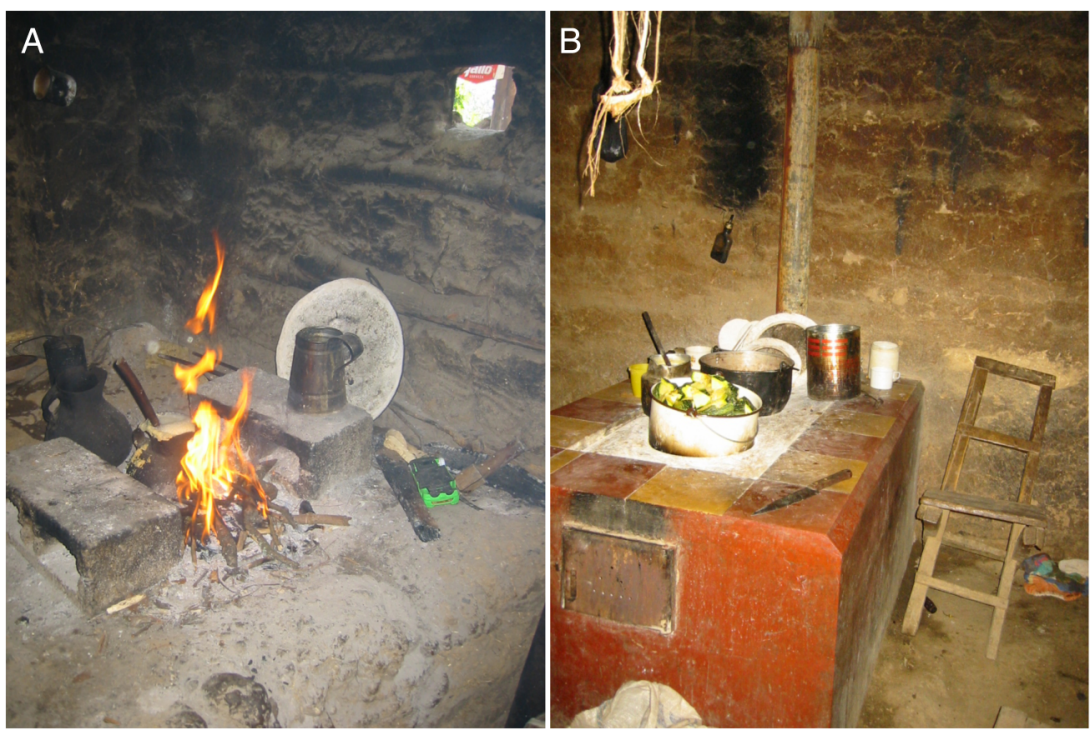
Table 4 Baseline spirometry, lung function growth and airflow obstruction by study group

\begin{tabular}{|c|c|c|c|c|}
\hline Baseline & $\begin{array}{l}\text { Group 1, } \\
\text { mean (SD) }\end{array}$ & $\begin{array}{l}\text { Group 2, } \\
\text { mean (SD) }\end{array}$ & $\begin{array}{l}\text { Group 3, } \\
\text { mean (SD) }\end{array}$ & p Value \\
\hline $\mathrm{FEV}_{1}(\mathrm{~L})$ & $0.918(0.2)$ & $0.911(0.2)$ & $0.823(0.2)$ & 0.19 \\
\hline FVC (L) & $1.03(0.2)$ & $1.01(0.2)$ & $0.87(0.2)$ & 0.16 \\
\hline $\mathrm{FEV}_{1} / \mathrm{FVC}$ & $0.90(0.06)$ & $0.90(0.06)$ & $0.89(0.06)$ & 0.56 \\
\hline $\mathrm{FEF}_{25-75}(\mathrm{~L})$ & $1.39(0.4)$ & $1.42(0.5)$ & $1.28(0.4)$ & 0.08 \\
\hline PEF $(L)$ & $2.27(0.5)$ & $2.30(0.6)$ & $2.17(0.5)$ & 0.22 \\
\hline Per cent predicted lung function at baseline* & Mean (SD) & Mean (SD) & Mean (SD) & \\
\hline $\mathrm{FEV}_{1}(\%)$ & $110(20)$ & $108(19)$ & $104(16)$ & 0.15 \\
\hline FVC (\%) & $115(23)$ & $112(19)$ & $109(16)$ & 0.16 \\
\hline $\mathrm{FEV}_{1} / \mathrm{FVC}(\%)$ & $95(6)$ & $96(6)$ & $95(6)$ & 0.54 \\
\hline $\mathrm{FEF}_{25-75}(\%)$ & $109(29)$ & $111(36)$ & $101(29)$ & 0.09 \\
\hline Annual changet & Mean $(95 \% \mathrm{Cl})$ & Mean $(95 \% \mathrm{Cl})$ & Mean $(95 \% \mathrm{Cl})$ & \\
\hline $\mathrm{FEV}_{1}$ (mL/year) & 144 (114 to 176$)$ & 100 (63 to 137$)$ & 109 (67 to 152$)$ & 0.14 \\
\hline FVC (mL/year) & $172(134$ to 209$)$ & 137 (96 to 177) & $146(102$ to 190$)$ & 0.43 \\
\hline $\mathrm{FEV}_{1} / \mathrm{FVC}$ (\%/year) & $-0.9(-2.1$ to 0.2$)$ & $-1.6(-2.8$ to -0.4$)$ & $-1.5(-3.7$ to 0.7$)$ & 0.76 \\
\hline $\mathrm{FEF}_{25-75}(\mathrm{~mL} / \mathrm{min} /$ year $)$ & 116 (31 to 202$)$ & $91(-16$ to 198$)$ & $89(-38$ to 217$)$ & 0.91 \\
\hline $\mathrm{PEF}(\mathrm{mL} / \mathrm{min} /$ year) & 405 (298 to 513 ) & 236 (108 to 365$)$ & 272 (141 to 402$)$ & 0.10 \\
\hline Airflow obstruction & $\mathrm{N}(\%)$ & $\mathrm{N}(\%)$ & $\mathrm{N}(\%)$ & \\
\hline Children with at least one $\mathrm{FEV}_{1} / \mathrm{FVC}<0.7$ & $6(3.4)$ & $5(2.8)$ & $6(4.0)$ & 0.83 \\
\hline
\end{tabular}

in air pollution history. In addition to the initial randomised design, the RESPIRE and CRECER studies are unique among biomass stove studies in several ways. Unlike many other studies, which either approximated biomass smoke exposure based on fuel or stove type or one-time ambient measurements, RESPIRE and CRECER featured detailed exposure measurements, with longitudinal collection of personal CO exposure. Additionally, in contrast to the cross-sectional nature of previous studies of biomass smoke exposure and children's respiratory health, CRECER is the first to examine the relationship between biomass smoke exposure and longitudinal measurement of lung function in children.

This study identified a statistically significant decrease in PEF growth among children in the RESPIRE control group (Group 2), whose families continued cooking over open fires for their first 18 months of life, compared with children in the RESPIRE intervention group (Group 1), whose households had chimney stoves installed within 6 months of birth (figure 2). However, while PEF measurements at individual time points can provide acute estimates of airflow through the bronchi and possible obstruction, the significance of a decrease in PEF growth over time is less clear. A borderline statistically significant decrease in $\mathrm{FEV}_{1}$ of $44 \mathrm{~mL} /$ year was also seen in Group 2 compared with Group 1. The clinical implications of this finding are more concrete; a difference in $\mathrm{FEV}_{1}$ growth of $44 \mathrm{~mL} /$ year or greater would amount to a large difference in achieved lung function over 20 years of lung growth. Decreased growth of other lung function variables was also seen in both Groups 2 and 3 compared with Group 1, though none reached a level of statistical significance. Exposure-response analyses showed a largely consistent pattern of reductions in lung function associated with increases in biomass smoke exposure during the first 18 months of life (table 6), though none reached a level of statistical significance.

We may have failed to show stronger relationships between biomass smoke exposure and lung function for several reasons.
The first is incomplete exposure reduction. Though biomass smoke exposure was lower following stove installation, there was continued heavy smoke exposure despite the chimney stove; overall, personal exposure reduction associated with the stove was substantially less than the reduction achieved by the stove in measured kitchen levels. ${ }^{9}{ }^{24}$ The resulting differences in smoke exposure between stove groups may not have been enough to result in large differences in lung function growth. Given the likely non-linear shape of the exposure-response curve for PM and respiratory health outcomes, ${ }^{30} 31$ the lack of exposure heterogeneity may have limited our ability to detect any significant differences in growth of lung function.

Additionally, it is possible that the period of differential biomass smoke exposure in RESPIRE (only 18 months) may not have been long enough to produce a persistent effect on lung function. Any transient effects on pulmonary development may have been compensated for by the time CRECER spirometry began at age 5. A previous study of children who moved from communities with high levels of outdoor air pollution to communities with lower levels of pollution found evidence of increases in previously depressed lung function growth, suggesting that pulmonary damage from pollutants may be reversible over time if exposures are reduced. ${ }^{8} 32$

Conversely, biomass smoke exposure during infancy may have caused lasting lung damage, but such damage may be subtle and take many years to become apparent. Of note, decreases in lung function growth were relatively similar in Groups 2 and 3, despite different durations of stove use; one possible explanation for this finding could be that the first 1-2 years of life, before either of these groups had stoves installed, might represent a particularly vulnerable period. This study had a relatively limited spirometry follow-up period; it is possible that even more significant differences in lung function would be seen with spirometry follow-up later into childhood and adulthood. The developing lung may be even more susceptible to environmental 
Table 5 Changes in annual lung function growth associated with stove group

\begin{tabular}{|c|c|c|c|c|c|c|c|c|c|c|c|c|c|c|c|}
\hline & \multicolumn{3}{|c|}{$\begin{array}{l}\mathrm{FEV}_{1} \text { (mL/year), coefficient }(95 \% \\
\mathrm{Cl}) \text {, } \\
\mathrm{n}=437\end{array}$} & \multicolumn{3}{|c|}{$\begin{array}{l}\text { FVC }(\mathrm{mL} / \text { year), } \\
\text { coefficient }(95 \% \mathrm{Cl}) \\
\mathrm{n}=407\end{array}$} & \multicolumn{3}{|c|}{$\begin{array}{l}\mathrm{FEV}_{1} / \mathrm{FVC}(\% / \text { year }) \\
\text { coefficient }(95 \% \mathrm{Cl}) \\
\mathrm{n}=407\end{array}$} & \multicolumn{3}{|c|}{$\begin{array}{l}\mathrm{FEF}_{25-75}(\mathrm{~mL} / \mathrm{min} / \text { year }) \text {, } \\
\text { coefficient }(95 \% \mathrm{Cl}) \text {, } \\
\mathrm{n}=407\end{array}$} & \multicolumn{3}{|c|}{$\begin{array}{l}\text { PEF (mL/min/year), } \\
\text { coefficient }(95 \% \mathrm{Cl}) \text {, } \\
\mathrm{n}=443\end{array}$} \\
\hline & B & $95 \% \mathrm{Cl}$ & $\mathrm{p}$ Value & $\boldsymbol{\beta}$ & $95 \% \mathrm{Cl}$ & $p$ Value & $\boldsymbol{\beta}$ & $95 \% \mathrm{Cl}$ & $p$ Value & $\boldsymbol{\beta}$ & $95 \% \mathrm{Cl}$ & $p$ Value & $\beta$ & $95 \% \mathrm{Cl}$ & p Value \\
\hline Group 1 & \multicolumn{3}{|c|}{ Reference group } & \multicolumn{3}{|c|}{ Reference group } & \multicolumn{3}{|c|}{ Reference group } & \multicolumn{3}{|c|}{ Reference group } & \multicolumn{3}{|c|}{ Reference group } \\
\hline \multicolumn{16}{|l|}{ Group 2} \\
\hline Unadjusted & -45 & -93 to 3 & 0.065 & -35 & -90 to 20 & 0.21 & -0.6 & -2.3 to 1.1 & 0.47 & -25 & -16 to 11 & 0.72 & -170 & -337 to -14 & 0.048 \\
\hline Adjusted* & -44 & -91 to 4 & 0.07 & -39 & -93 to 16 & 0.16 & -0.6 & -2.2 to 1.1 & 0.52 & -23 & -158 to 111 & 0.73 & -173 & -341 to -7 & 0.041 \\
\hline \multicolumn{16}{|l|}{ Group 3} \\
\hline Unadjusted & -35 & -88 to 17 & 0.18 & -25 & -83 to 32 & 0.39 & -0.5 & -3.0 to 2.0 & 0.69 & -27 & -180 to 126 & 0.73 & -134 & -303 to 35 & 0.12 \\
\hline Adjusted & -39 & -91 to 13 & 0.14 & -36 & -94 to 22 & 0.23 & -0.4 & -2.9 to 2.2 & 0.78 & -19 & -173 to 134 & 0.80 & -137 & -303 to 28 & 0.10 \\
\hline
\end{tabular}

*Final model adjusted for age, gender, baseline height, annual change in height, maternal education and secondhand smoke.

PEF, peak expiratory flow.

Bold $=$ statistical significance $\mathrm{p}<0.05$

Table 6 Changes in annual lung function growth associated with early life personal carbon monoxide (CO) exposures

\begin{tabular}{|c|c|c|c|c|c|c|c|c|c|c|c|c|c|c|c|}
\hline & \multicolumn{3}{|c|}{$\begin{array}{l}\mathrm{FEV}_{1}(\mathrm{~mL} / \mathrm{year}), \\
\text { coefficient }(95 \% \mathrm{Cl}), \\
\mathrm{n}=437\end{array}$} & \multicolumn{3}{|c|}{$\begin{array}{l}\text { FVC }(\mathrm{mL} / \text { year), } \\
\text { coefficient }(95 \% \mathrm{Cl}) \text {, } \\
\mathrm{n}=407\end{array}$} & \multicolumn{3}{|c|}{$\begin{array}{l}\mathrm{FEV}_{1} / \mathrm{FVC}(\% / \text { year), } \\
\text { coefficient }(95 \% \mathrm{Cl}), \\
\mathrm{n}=407\end{array}$} & \multicolumn{3}{|c|}{$\begin{array}{l}\mathrm{FEF}_{25-75}(\mathrm{~mL} / \mathrm{min} / \text { year}) \\
\text { coefficient }(95 \% \mathrm{Cl}) \text {, } \\
\mathrm{n}=407\end{array}$} & \multicolumn{3}{|c|}{$\begin{array}{l}\text { PEF (mL/min/year), } \\
\text { coefficient }(95 \% \mathrm{Cl}) \text {, } \\
\mathrm{n}=443\end{array}$} \\
\hline & $\boldsymbol{\beta}^{*}$ & $95 \% \mathrm{Cl}$ & $\mathrm{p}$ Value & $\beta^{*}$ & $95 \% \mathrm{Cl}$ & $\mathrm{p}$ Value & $\boldsymbol{\beta}^{*}$ & $95 \% \mathrm{Cl}$ & $\mathrm{p}$ Value & $\boldsymbol{\beta}^{*}$ & $95 \% \mathrm{Cl}$ & $\mathrm{p}$ Value & $\boldsymbol{\beta}^{*}$ & $95 \% \mathrm{Cl}$ & $p$ Value \\
\hline \multicolumn{16}{|c|}{ CO during RESPIRE $\dagger$} \\
\hline Unadjusted & -2.6 & -7.3 to 1.9 & 0.26 & -2.0 & -7.0 to 3.0 & 0.43 & -0.02 & -0.2 to 0.2 & 0.82 & -1.8 & -16 to 12 & 0.80 & -5.7 & -21 to 9.5 & 0.46 \\
\hline Adjusted $¥$ & -2.4 & -7.0 to 2.3 & 0.32 & -1.7 & -6.8 to 3.5 & 0.52 & -0.04 & -0.2 to 0.1 & 0.68 & -2.1 & -15 to 11 & 0.76 & -5.6 & -21 to 9.4 & 0.46 \\
\hline
\end{tabular}

${ }^{*} \beta$-Coefficients represent the change in lung function growth for a $10 \%$ unit increase in $\mathrm{CO}$

fFor Group 3 only, the study child's early life exposures were estimated based on CO measurements of their infant sibling, collected prior to stove installation during Childhood Exposure to Respirable Particulate Matter in the first 18 months of life.

†Final model adjusted for age, gender, baseline height, annual change in height, maternal education and secondhand smoke.

PEF, peak expiratory flow; RESPIRE, Randomised Exposure Study of Pollution Indoors and Respiratory Effects. 
exposures during the in utero period. While $\sim 50 \%$ of the RESPIRE children were recruited during pregnancy, the mean in utero time with chimney stove use was only 40 days. ${ }^{9}$ Thus, the RESPIRE intervention may not have been optimally timed to have the greatest impact on growth of lung function.

Our data provide insight into patterns of biomass smoke exposure in the study population. Exposure levels during the first 18 months of life were lowest in Group 1, as expected, as these households received stoves prior to the initiation of measurements, while households in the other two groups did not. A decrease of $46 \%$ in personal exposure levels from baseline was seen in this group following stove installation. Comparisons of early childhood exposures between RESPIRE participants and new CRECER households should be interpreted with some caution; early life exposure estimates for new CRECER household participants were extrapolated from measurements on their younger siblings, as described above. We believe this assumption is valid because the three stove groups were similar with respect to baseline demographics and there is little socioeconomic mobility or change in cooking practices over time in this population.

Biomass smoke exposure levels during the CRECER follow-up period revealed a different pattern. Participants in both RESPIRE groups had lower exposure levels during CRECER than during the first 18 months of life. For the RESPIRE control group (Group 2), this decrease is likely due at least in part to stove installation, which occurred between the two measurement periods. Other factors likely contributed to the decline in both groups; as children grew older, they may have spent less time indoors exposed to higher levels of biomass smoke, or households may have changed their cooking practices to reduce exposure due to their participation in the RESPIRE trial (the Hawthorne effect). Compared with Groups 1 and 2, participants in Group 3 had a significantly higher average personal CO exposure during the CRECER period; this difference is likely attributable to continued cooking over open fires, as the reported exposure measurements for this group were taken prior to stove installation.

Another potential limitation is exposure misclassification based on our use of periodic personal $\mathrm{CO}$ measurements as a proxy for cumulative exposure. More detailed exposure data, including ambient measurements, more intensive personal measurements and questionnaire data, were collected on a subset of individuals as part of both RESPIRE and CRECER, but more complex analysis of these data goes beyond the scope of the present study.

Increased risk of asthma morbidity is a well-documented effect of outdoor air pollution, ${ }^{33}$ but few studies have examined the effect of biomass smoke exposure on asthma risk, and their results have generally been mixed. ${ }^{6}{ }^{34-37}$ Even fewer studies have looked specifically at this relationship in children. Though the present study was not designed to specifically examine childhood asthma, there was little clinically apparent airflow obstruction in the lung function testing that was performed. The hygiene hypothesis, which posits that increased early childhood exposure to diverse microbial and environmental antigensoften occurring in rural or lower income settings-decreases risk of atopic disease, offers one possible explanation. ${ }^{38}$ Genetic factors may also be involved; a study of asthma in Hispanic and non-Hispanic children in the USA found that rates were significantly lower in children of Mexican heritage than in other groups. ${ }^{39}$

We also sought to compare lung function measurements with predicted reference values based on age, height and gender. The GLFI equations ${ }^{27}$ include children aged 3 and older and were used here to calculate predicted lung function. However, these equations appear to underestimate lung function in this population; average per cent predicted $\mathrm{FEV}_{1}, \mathrm{FVC}$ and $\mathrm{FEF}_{25-75}$ were all $>100 \%$. This is consistent with past studies that have found both the GLFI and National Health and Nutrition Examination Survey (NHANES) equations for Mexican-American children to underestimate lung function in cohorts of children in Mexico City. ${ }^{10}{ }^{40}$ Differences in these studies were attributed to greater sitting height (and therefore lung volume) in Mexican children, as well as higher altitude; similar factors may be at work in this Guatemalan population. Based on this study's findings, the GLFI reference equations may not be optimal for clinical use in this population.

In conclusion, the findings presented here represent the first longitudinal analysis of the relationship between childhood biomass smoke exposure and lung function growth, using follow-up data from a randomised stove intervention featuring detailed exposure measurements. PEF growth was found to be lower in children whose families did not receive a chimney stove until 18 months of life, compared with children who received a stove at birth. Children with longer durations of heavier smoke exposure also had lower $\mathrm{FEV}_{1}$ growth, though this effect did not reach a level of statistical significance. Further studies involving cleaner stoves or fuels or longer follow-up periods are needed to provide additional insight on this topic.

Acknowledgements The authors thank Alisa Jenny for project management, Carolina Romero and Anaité Diaz for organising the fieldwork, Rudinio Acevedo for data management and Andrea Kuster, Ericka Barrios and Micaela Isidro for data collection. Most importantly, this study would not have been possible without the hard work and cooperation of the San Lorenzo field team and study participants.

Contributors Involvement in the conception, hypothesis delineation and design of the study: NGB, KRS, JRB; acquisition of the data or the analysis and interpretation of such information: APH, MJG, JKM, JVD, LMT, NGB, KRS, JRB; writing the article or substantial involvement in its revision prior to submission: $A P H, M J G, J K M, ~ J V D$, LMT, NGB, KRS, JRB.

Funding Funding support was provided by the National Institute of Environmental Health Sciences (NIEHS R01ES010178) and the National Center for Advancing Translational Sciences (UCSF-CTSI Grant Number UL1 TR000004).

Competing interests None declared.

Ethics approval University of California, Berkeley; Universidad del Valle de Guatemala; University of California, San Francisco.

Provenance and peer review Not commissioned; externally peer reviewed.

\section{REFERENCES}

1 Rehfuess E, Mehta S, Prüss-Üstün A. Assessing household solid fuel use: multiple implications for the Millennium Development Goals. Environ Health Perspect 2006:114:373-8.

2 Naeher LP, Brauer M, Lipsett $M$, et al. Woodsmoke health effects: a review. Inhal Toxicol 2007;19:67-106.

3 Bonjour S, Adair-Rohani $\mathrm{H}$, Wolf J, et al. Solid fuel use for household cooking: country and regional estimates for 1980-2010. Environ Health Perspect 2013;121:784-90.

4 Fullerton DG, Bruce N, Gordon SB. Indoor air pollution from biomass fuel smoke is a major health concern in the developing world. Trans $R$ Soc Trop Med Hyg 2008; 102:843-51.

5 Lim SS, Vos T, Flaxman AD, et al. A comparative risk assessment of burden of disease and injury attributable to 67 risk factors and risk factor clusters in 21 regions, 1990-2010: a systematic analysis for the Global Burden of Disease Study 2010. Lancet 2012;380:2224-60.

6 Diette GB, Accinelli RA, Balmes JR, et al. Obstructive lung disease and exposure to burning biomass fuel in the indoor environment. Glob Heart 2012;7:265-70.

7 Gordon SB, Bruce NG, Grigg J, et al. Respiratory risks from household air pollution in low and middle income countries. Lancet Respir Med 2014;2:823-60.

8 Narayanan M, Owers-Bradley J, Beardsmore CS, et al. Alveolarization continues during childhood and adolescence: new evidence from helium-3 magnetic resonance. Am J Respir Crit Care Med 2012;185:186-91.

9 Smith KR, McCracken JP, Weber MW, et al. Effect of reduction in household air pollution on childhood pneumonia in Guatemala (RESPIRE): a randomised controlled trial. Lancet 2011;378:1717-26. 
10 Perez-Padilla R, Schilmann A, Riojas-Rodriguez H. Respiratory health effects of indoor air pollution. Int I Tuberc Lung Dis 2010;14:1079-86.

11 Dherani M, Pope D, Mascarenhas M, et al. Indoor air pollution from unprocessed solid fuel use and pneumonia risk in children aged under five years: a systematic review and meta-analysis. Bull World Health Organ 2008;86:390C-8C.

12 Gauderman WJ, McConnell R, Gilliland F, et al. Association between air pollution and lung function growth in southern California children. Am J Respir Crit Care Med 2000;162:1383-90.

13 Gauderman WJ, Avol E, Gilliland F, et al. The effect of air pollution on lung development from 10 to 18 years of age. N Engl J Med 2004;351:1057-67.

14 Jedrychowski W, Flak E, Mróz E. The adverse effect of low levels of ambient air pollutants on lung function growth in preadolescent children. Environ Health Perspect 1999:107:669-74.

15 Rojas-Martinez R, Perez-Padilla R, Olaiz-Fernandez G, et al. Lung function growth in children with long-term exposure to air pollutants in Mexico City. Am J Respir Crit Care Med 2007;176:377-84.

16 Horak F Jr, Studnicka M, Gartner C, et al. Particulate matter and lung function growth in children: a 3-yr follow-up study in Austrian schoolchildren. Eur Respir J 2002;19:838-45.

17 Azizi BH, Henry RL. Effects of indoor air pollution on lung function of primary school children in Kuala Lumpur. Pediatr Pulmonol 1990;9:24-9.

18 Gharaibeh NS. Effects of indoor air pollution on lung function of primary school children in Jordan. Ann Trop Paediatr 1996;16:97-102.

19 Behera D, Sood P, Singh S. Passive smoking, domestic fuels and lung function in north Indian children. Indian J Chest Dis Allied Sci 1998;40:89-98.

20 Oloyede IP, Ekrikpo UE, Ekanem EE. Lung function indices of children exposed to wood smoke in a fishing port in South-South Nigeria. J Trop Pediatr 2013:59:399-402.

21 Padhi BK, Padhy PK. Domestic fuels, indoor air pollution, and children's health. Ann N Y Acad Sci 2008;1140:209-17.

22 Rinne ST, Rodas EJ, Bender BS, et al. Relationship of pulmonary function among women and children to indoor air pollution from biomass use in rural Ecuador. Respir Med 2006;100:1208-15.

23 Roy A, Chapman RS, Hu W, et al. Indoor air pollution and lung function growth among children in four Chinese cities. Indoor Air 2012;22:3-11.

24 Smith KR, McCracken JP, Thompson L, et al. Personal child and mother carbon monoxide exposures and kitchen levels: methods and results from a randomized trial of woodfired chimney cookstoves in Guatemala (RESPIRE). J Expo Sci Environ Epidemiol 2010;20:406-16.

25 Smith-Sivertsen T, Díaz E, Pope D, et al. Effect of reducing indoor air pollution on women's respiratory symptoms and lung function: the RESPIRE Randomized Trial, Guatemala. Am J Epidemiol 2009;170:211-20.
26 Northcross A, Chowdhury Z, McCracken J, et al. Estimating personal PM2.5 exposures using $\mathrm{CO}$ measurements in Guatemalan households cooking with wood fuel. J Environ Monit 2010;12:873-8.

27 Quanjer PH, Stanojevic S, Cole TJ, et al. Multi-ethnic reference values for spirometry for the 3-95-yr age range: the global lung function 2012 equations. Eur Respir J 2012;40:1324-43.

28 Lam N, Nicas M, Ruiz-Mercado I, et al. Non-invasive measurement of carbon monoxide burden in Guatemalan children and adults following wood-fired temazcal (sauna-bath) use. J Environ Monit 2011;13:2172-81.

29 Thompson LM, Clark M, Cadman B, et al. Exposures to high levels of carbon monoxide from wood-fired temazcal (steam bath) use in highland Guatemala. Int J Occup Environ Health 2011;17:103-12.

30 Burnett RT, Pope CA III, Ezzati M, et al. An integrated risk function for estimating the global burden of disease attributable to ambient fine particulate matter exposure. Environ Health Perspect 2014;122:397-403.

31 Smith KR, Bruce N, Balakrishnan K, et al. Millions dead: how do we know and what does it mean? Methods used in the comparative risk assessment of household air pollution. Annu Rev Public Health 2014;35:185-206.

32 Avol EL, Gauderman WJ, Tan SM, et al. Respiratory effects of relocating to areas of differing air pollution levels. Am J Respir Crit Care Med 2001;164:2067-72.

33 Guarnieri M, Balmes JR. Outdoor air pollution and asthma. Lancet 2014;383:1581-92.

34 Agrawal S. Effect of indoor air pollution from biomass and solid fuel combustion on prevalence of self-reported asthma among adult men and women in India: findings from a nationwide large-scale cross-sectional survey. J Asthma 2012;49: 355-65.

35 Po JY, FitzGerald JM, Carlsten C. Respiratory disease associated with solid biomass fuel exposure in rural women and children: systematic review and meta-analysis. Thorax 2011;66:232-9.

36 Thacher JD, Emmelin A, Madaki AJ, et al. Biomass fuel use and the risk of asthma in Nigerian children. Respir Med 2013;107:1845-51.

37 Trevor J, Antony V, Jindal SK. The effect of biomass fuel exposure on the prevalence of asthma in adults in India—review of current evidence. J Asthma 2014:51:136-41.

38 Okada $\mathrm{H}$, Kuhn $\mathrm{C}$, Feillet $\mathrm{H}$, et al. The 'hygiene hypothesis' for autoimmune and allergic diseases: an update. Clin Exp Immunol 2010;160:1-9.

39 Lara M, Akinbami L, Flores G, et al. Heterogeneity of childhood asthma among Hispanic children: Puerto Rican children bear a disproportionate burden. Pediatrics 2006;117:43-53.

40 Martínez-Briseño D, Fernández-Plata R, Gochicoa-Rangel L, et al. Longitudinal lung function growth of Mexican children compared with international studies. PLOS One 2013:8:e77403. 